\title{
Eighteen month follow up of Helicobacter pylori positive children treated with amoxycillin and tinidazole
}

\author{
G Oderda, D Vaira, C Ainley, J Holton, J Osborn, F Altare, N Ansaldi
}

\begin{abstract}
Sixty three children with dyspepsia (mean age 12 years, range one to $18, M / F 41 / 22$ ) were Helicobacter pylori positive by histology of gastric antral biopsy specimens and were treated with a six week course of amoxycillin $(50 \mathrm{mg} / \mathrm{kg}$ ) and tinidazole $(20 \mathrm{mg} / \mathrm{kg})$. The endoscopic diagnoses were: normal (16), nodular gastritis (19), oesophagitis (four), duodenal ulcer (13), and gastric ulcer (11). H pylori was eradicated in $54(87 \%)$ and histological gastritis resolved in 51 and was improved in the other three. Repeat investigation was offered at six monthly intervals. Reinfection was found in three of $34(9 \%)$ at six months, in none of 22 at 12 months, and in two of $18(11 \%)$ at 18 months, yielding an 18 month cumulative relapse rate of $20 \%$. Children with persisting infection despite treatment remained positive during follow up. Serum $H$ pylori IgG concentrations fell after treatment $(p<0.001)$, and for individual children during follow up there was a progressive decline, but an increased concentration indicated recurrence. After eradication of $\boldsymbol{H}$ pylori by combined amoxycillin and tinidazole treatment, only a minority of children relapse during the ensuing 18 months.

(Gut 1992; 33: 1328-1330)
\end{abstract}

Several of the difficulties recently posed by the treatment of Helicobacter pylori ( $H$ pylori) have been resolved. Thus, while single drug treatment of $H$ pylori with bismuth compounds or antibiotics may clear the organism, ${ }^{1}$ recrudescence is very common, and for effective eradication (defined as the absence of infection four weeks after completion of treatment, ${ }^{2}$ combined treatment of bismuth with antibiotics is required. ${ }^{134}$ Because of concern about possible toxicity, bismuth preparations are not licensed for children in several countries including Italy and the UK. We have previously shown that combined amoxycillin and tinidazole treatment of $32 \mathrm{H}$ pylori positive children eradicated the infection in more than $90 \%$ of cases.

Little is known of the spread of $H$ pylori, but in adults successfully treated with bismuth/ antibiotic combinations, relapse during long term follow up has been unusual, and reported 12 month recurrence rates vary between three and $11 \% .^{1{ }^{34}}$ Patterns of spread, however, may differ in children with an increased risk of relapse as 12 of the 32 children with $H$ pylori successfully treated with combined amoxycillin and tinidazole were reinvestigated six months after completing treatment, and infection had recurred in three (25\%). ${ }^{5}$ Therefore it has not been clear if treatment of children with $H$ pylori results in long term benefit. We have now treated a total of 63 children positive for $H$ pylori with combined tinidazole and amoxycillin, and to determine long term results they have been offered reinvestigation at six monthly intervals for up to 18 months.

\section{Methods}

\section{SUBJECTS}

Between February 1987 and December 1989 children with upper abdominal pain undergoing endoscopy in the Department of Paediatric Gastroenterology of the University of Turin, Italy, were investigated for $H$ pylori. A fasting blood sample was taken. Serum $H$ pylori IgG and pepsinogen I concentrations were measured as previously described, ${ }^{6}$ and serum gastrin assayed by the method described by Ansaldi et al. ${ }^{7}$ Upper gastrointestinal endoscopy was carried out after oral diazepam sedation and tetracaine throat anaesthesia using an Olympus XP20 gastroscope. Gastric antral biopsy specimens were taken for histology, culture and urease testing. The gastroscope and biopsy forceps were disinfected in $2 \%$ glutaraldehyde after each use.

In common with other studies the presence of $H$ pylori on histology was taken as diagnostic of infection. ${ }^{89} H$ pylori positive children were treated with a six week course of amoxycillin (50 $\mathrm{mg} / \mathrm{kg} /$ day) and tinidazole $(20 \mathrm{mg} / \mathrm{kg} /$ day $)$, and reinvestigated four weeks after stopping treatment. Children in whom $H$ pylori persisted were treated with a further six week course of amoxycillin and tinidazole. Repeat investigation was offered at six monthly intervals for 18 months.

\section{STATISTICAL ANALYSIS}

Statistical analysis was performed by two tailed Mann-Whitney U test after Log transformation. The study was approved by the Piedmont Regional Ethical Committee and by the University of Turin. Fully informed parental consent was obtained.

\section{Results}

Sixty three of 320 children (20\%) having endoscopy were $H$ pylori positive. Their mean age was 12 years (range one to 18 ), and 42 were boys. There were 16 with normal endoscopic appearances, 19 with macroscopic nodular gastritis, 13 with duodenal ulcer, 11 with gastric ulcer, and four with oesophagitis. Culture was positive in 53 $(84 \%)$, and urease testing in $51(81 \%)$, and there 
TABLE I Number of children positive for $\mathrm{H}$ pylori by histology, urease testing and culture of antral biopsy specimens - before treatment with amoxcyllin and tinidazole, one month after treatment, and relapsing during follow up. Percentage value in parentheses

\begin{tabular}{|c|c|c|c|c|}
\hline & $\begin{array}{l}\text { Microscopy } \\
\text { (Giemsa) }\end{array}$ & $\begin{array}{l}\text { Histological } \\
\text { gastritis }\end{array}$ & Urease test & Culture \\
\hline $\begin{array}{l}\text { Before treatment } \\
n=63\end{array}$ & $63(100)$ & $63(100)$ & $51(81)$ & $53(84)$ \\
\hline $\begin{array}{l}\text { After treatment } \\
1 \text { month } \\
n=63\end{array}$ & $10(16)$ & $10(16)$ & $1(2)$ & $5(88)$ \\
\hline 6 months & $3(9)$ & $3(9)$ & $1(3)$ & $1(3)$ \\
\hline $\begin{array}{c}12 \text { months } \\
n=22\end{array}$ & 0 & 0 & 0 & 0 \\
\hline $\begin{array}{c}18 \text { months } \\
n=18\end{array}$ & $2(10)$ & $2(10)$ & 0 & $1(5)$ \\
\hline
\end{tabular}

TABLE II Serum IgG, pepsinogen I and gastrin concentrations before and after treatment with amoxycillin and tinidazole. Mean optical density $(S D)$

\begin{tabular}{llll}
\hline & $I g G$ & Pepsinogen I & Gastrin \\
\hline $\begin{array}{l}\text { Before treatment } \\
(\mathrm{n}=63)\end{array}$ & $553(147)$ & $75(28)$ & \\
$\begin{array}{l}\text { One month after treatment } \\
\text { HP negative }(\mathrm{n}=54)\end{array}$ & $434(148) \ddagger$ & $50(17) \ddagger$ & $33(20)$ \\
$\begin{array}{l}\text { HP positive }(\mathrm{n}=9) \\
\text { Six months after treatment }\end{array}$ & $663(157)$ & $75(25)$ & $38(13)$ \\
$\quad$ HP negative $(\mathrm{n}=31)$ & $396(146) \ddagger$ & $51(23) \ddagger$ & $31(7) \dagger$ \\
HP positive $(\mathrm{n}=6)$ & $608(170)$ & $80(34)$ & $37(7)$ \\
Twelve months after treatment & $333(138) \ddagger$ & $44(14) \ddagger$ & $34(7) \dagger$ \\
$\quad$ HP negative $(\mathrm{n}=22)$ & $581(40)$ & $60(4)$ & $29(4)$ \\
HP positive $(\mathrm{n}=2)$ & $288(98) \ddagger$ & $47(15) \ddagger$ & $32(7)$ \\
Eighteen months after treatment & $597(149)$ & $57(5)$ & $31(4)$ \\
$\quad$ HP negative $(\mathrm{n}=16)$ & HP positive $(\mathrm{n}=4)$ & &
\end{tabular}

${ }^{\star} \mathrm{p}<0.05, \dagger \mathrm{p}<0 \cdot 01, \neq \mathrm{p}<0.001$ compared with level before treatment. $\mathrm{HP}=$ Helicobacter pylori. tomatic reinfection. Three of the 10 children in whom $H$ pylori persisted despite treatment were also investigated, and all remained infected but asymptomatic. There were no recurrent peptic ulcers.

At 12 months, 24 children (38\%) were reinvestigated. Twenty two in whom $H$ pylori had been eradicated all remained negative, including four children with further pain. Two of the 10 children with persisting $H$ pylori after treatment were investigated and remained infected but asymptomatic. As at six months, there were no recurrent peptic ulcers.

At 18 months, 20 children (32\%) were reinvestigated. Sixteen of 18 in whom $H$ pylori had been eradicated remained negative $(89 \%)$, including two with further pain, and two children had asymptomatic reinfection. Two of the 10 children with persisting $H$ pylori after treatment were investigated and remained infected; one had an asymptomatic recurrent duodenal ulcer and the other had further pain.

The recurrence rates for the children in whom $H$ pylori was eradicated and who underwent reinvestigation were: $9 \%$ at six months; $0 \%$ at 12 months; and $11 \%$ at 18 months; yielding a cumulative relapse rate of $20 \%$.

During the 18 month follow up period, concentrations of serum $H$ pylori IgG, pepsinogen I and gastrin remained low in children free from infection (Table II). Persisting or recurrent infection was invariably associated with a rise in serum $H$ pylori IgG concentration, but pepsinogen I and gastrin concentration were less reliable (Table II).

with negative histology (Table I).

All 63 children completed six weeks of combined amoxycillin and tinidazole treatment. Side effects occurred in six children (nausea in three, and vomiting, vertigo and skin rash each affected one child), but these were mild and it was not necessary to abandon treatment.

Four weeks after stopping treatment, $H$ pylori had been eradicated in 54 children $(86 \%)$. Fifty one had normal gastric histology, and in the other three gastritis was improved. Ten children (16\%) remained $H$ pylori positive, and all had persisting antral gastritis although in seven the inflammation had improved. $H$ pylori were cultured in five of the 10 children, but urease testing was positive in only one child. None of these persistently $H$ pylori positive children had infection eradicated by a further six week course of amoxycillin and tinidazole.

Serum $H$ pylori IgG, pepsinogen I and gastrin concentrations were all decreased four weeks after stopping treatment (IgG-19\%, 95\% confidence interval $(\mathrm{Cl})-13$ to $-24 \%, \mathrm{p}<0.001$; pepsinogen $\mathrm{I}-27 \%, 95 \% \mathrm{Cl}-20$ to $-34 \%$, $\mathrm{p}<0.001$; gastrin $-24 \%, 95 \% \mathrm{Cl}-17$ to $-31 \%$, $\mathrm{p}<0.001$, Table II). Serum IgG concentrations fell in all 54 children in whom infection had been eradicated, and serum pepsinogen I and gastrin concentrations fell in $49(91 \%)$ and $42(78 \%)$ of these children respectively.

At six months, 37 children (59\%) were reinvestigated. Thirty one of $34(91 \%)$ in whom $H$ pylori had been eradicated remained negative for infection, including five children with further abdominal pain, and three children had asymp-

\section{Discussion}

Recent investigation has shown that combined treatment with bismuth preparations and/or antibiotics will eradicate $H$ pylori in the majority of infected subjects, and a beneficial effect on associated gastrointestinal pathology has been shown. ${ }^{13-5}$ Little is known, however, of the means of the spread of $H$ pylori, and therefore if recurrent infection proved frequent, the advisability of treating $H$ pylori would have been cast into serious doubt. Fortunately, the available information on the subsequent course of adults successfully treated for $H$ pylori infection indicates a low relapse rate. During 12 months follow up, Marshall et al found that three of 27 patients (11\%) relapsed, ${ }^{1}$ Rauws et al one of 21 $(5 \%),{ }^{3}$ and George et al two of $73(3 \%) .{ }^{+}$George et al extended the follow up period to 24 months in 57 of their patients, and all remained free from recurrent $H$ pylori. Although preliminary results suggested a much higher relapse rate of $25 \%$ at six months in children successfully treated with combined amoxycillin and tinidazole, 5 it has been shown that only a minority of a larger number of children relapse, and recurrence rates of $9 \%$ at 12 months, and $20 \%$ at 18 months were seen. Nevertheless, these rates are higher than in adults, perhaps reflecting different patterns of spread and an increased risk of reinfection. Increased prevalence rates of $H$ pylor $i$ within the families of infected children have been found, ${ }^{10-12}$ suggesting that person-to-person spread from other family members is an important source of 
infection and therefore also of recurrence. This source appears less common in adults for whom there is no increased intrafamily frequency of $H$ pylori compared with controls,${ }^{13}$ and for whom there is some evidence of occupational exposure.$^{14}$ is Further work on the spread of $H$ pylori is required.

Six weeks combined amoxycillin and tinidazole treatment is not in line with current trends with shorter courses of treatment, but was selected four years ago as the regime most likely to be effective. Similarly, the problem of metronidazole and tinidazole resistance as a cause of treatment failure was not known, and at that time a repeat course of amoxycillin and tinidazole was considered not unreasonable for failure of eradication.

Marshall et al also showed in adults that if $H$ pylori was not eradicated, infection persisted during follow up for 12 months, ${ }^{1}$ and the present study shows that this is also true for children.

Unfortunately the follow up of the 63 children was incomplete, but there was no evidence that those children reinvestigated were unrepresentative or that the absence of data from those lost to follow materially altered the results.

Most of the children had normal macroscopic appearances or antral gastritis at initial endoscopy, and therefore had $H$ pylori positive nonulcer dyspepsia. Most of those successfully treated were symptom free on follow up suggesting a causal link, but several children had asymptomatic relapse and others remaining $H$ pylori negative developed recurrent abdominal pain. Therefore, as in adult non-ulcer dyspepsia, it is not clear whether eradication of $H$ pylori improves symptoms in children. At a practical level $H$ pylori status cannot be predicted with certainty from symptoms. The present study has also shown, however, that during prolonged follow up, as in short term healing studies, ${ }^{16}$ serum $H$ pylori IgG concentrations accurately reflect $H$ pylori status whereas serum pepsinogen I and gastrin concentrations are unreliable. $H$ pylori can be diagnosed without endoscopy by either serology or breath testing after the administration of $13 \mathrm{C}$-urea, ${ }^{17}$ but serology has the advantage of simplicity. In children particularly, serum IgG concentrations are likely to provide a useful non-invasive means of assessing $H$ pylori status.
In conclusion, this study has shown a $20 \%$ relapse rate during 18 months follow up in children successfully treated for $H$ pylori by combined amoxycillin and tinidazole therapy, and confirmed the usefulness of serum IgG titre as an indicator of infection.

We thank the Central Research Fund of London University for financial support.

1 Marshall BJ, Goodwin CS, Warren JR, Murray R, Blincow ED, Blackbourn SJ, et al. Prospective double-blind trial of duodenal ulcer relapse after eradication of Campylobacter pylori. Lancet 1988; ii: $1437-42$.

2 Weil J, Bell GD, Jones PH, Gant P, Trowell JE, Harrison G. 'Eradication' of Campylobacter pylori: are we being misled? Lancet 1988; ii: 1245 .

3 Rauws EAJ, Tytgat GNJ. Cure of duodenal ulcer associated with eradication of Helicobacter pylori. Lancet 1990; ii: $1233-5$

4 George LL, Borody TJ, Andrews P, Devine M, Moore-Jones $\mathrm{D}$, Walton $\mathrm{M}$, et al. Cure of duodenal ulcer relapse after eradication of Helicobacter pylori. Med $\mathcal{F}$ Aust 1990; 153: 145-9.

5 Oderda G, Vaira D, Holton J, Ainley C, Altare F, Ansaldi N. Amoxycillin plus tinidozole for Campylobacter pylori gastritis in children: assessment by serum IgG antibody, pepsinogen I, and gastrin levels. Lancet 1989; i: $690-2$.

6 Oderda G, Vaira D, Holton J, Dowsett JF, Ansaldi N. Serum pepsinogen $I$ and $\operatorname{lgG}$ antibody to Campylobacter pylori in non-specific abdominal pain in childhood. Gut 1989; 30: non-speci.

7 Ansaldi N, Santini B, Barbera C, Oderda G, Dell'Olio D. Fasting serum gastrin levels and gastric acid output in children. Ital f Pediat 1978; 4: 329-35.

8 Peterson WL, Lee E, Feldman M. Relationship between Campylobacter pylori and gastritis in healthy humans after administration of placebo or indomethacin. Gastroenterology 1988; 95: 1185-97.

9 Rathbone BJ, Wyatt J, Heatley RV. Symptomatology in C pylori-positive and -negative non-ulcer dyspepsia. Gut 1988; 29: A1473.

10 Mitchell HM, Bohane TD, Berkowicz J, Hazell SL, Lee A. Antibody to Campylobacter pylori in families of index children with gastrointestinal illness due to Campylobacter children with gastrointestinal

11 Drumm B, Perez-Perez GI, Blaser MJ, Sherman PM. Intrafamily clustering of Helicobacter pylori infection. $N$ Engl f Med 1990; 322: 359-63.

2 Oderda G, Vaira D, Holton J, Ainley C, Altare F, Boero A, et al. Helicobacter pylori in children with peptic ulcer and their families. Dig Dis Sci 1991; 36: 572-6.

13 Jones DM, Eldridge J, Whorwell PJ. Antibodies to Campylobacter pyloridis in household contacts of infected patients. $B M \mathcal{F} 1987 ; 294: 615$.

14 Vaira D, D'Anastasio C, Holton J, Dowsett JF, Londei M, Bertone $F$, et al. Campylobacter pylori in abattoir workers: is it a zoonosis? Lancet 1988 ; ii: $725-6$.

15 Mitchell HM, Lee A, Carrick J. Increased incidence of Campylobacter pylori infection in gastroenterologists: further evidence to support person-to-person transmission further evidence to support person-to-person transmission

16 Vaira D, Holton J, Cairns SR, Falzon M, Polydorou A, Dowsett JF, et al. Antibody titres to Campylobacter pylori after treatment for gastritis. BMF 1988; 297: 397

1 Graham DY, Klein PD, Evans DJ, Evans DG, Alpert LC, Operkun AR, et al. Campylobacter pylori detected non invasively by the 13C-urea breath test. Lancet 1987 ; i: 174-7. 